\title{
Learning the language of earth science: Middle school students' explorations of rocks and minerals
}

\author{
Angelia Reid-Griffin ${ }^{1 *}$ \\ ${ }^{1}$ University of North Carolina Wilmington, USA
}

\begin{abstract}
The approaches and interpretations of a class of 6th graders and a class of 8th graders in a U.S. middle school asked to engage in tasks that involved using observations to describe and classify samples is the subject of this paper. Overall 8th graders were better able to perform the tasks, suggesting a developmental advantage aspect. However, the descriptions of the rock and mineral samples recorded by students can be considered salient for identification purposes. However, the descriptions were not recognized as salient features by most of the grade 6th and 8th U.S. students.
\end{abstract}

\author{
Keywords \\ geology, \\ earth science, \\ perception, \\ middle school, \\ structure

\begin{tabular}{rr} 
Received: & 29 Jan 2016 \\
Revised: & 12 Feb 2016 \\
Accepted: & 5 Mar 2016 \\
\hline DOI: $10.20897 /$ lectito. 201621
\end{tabular}

\section{INTRODUCTION}

The National Science Education Standards outlined a developmentally sound scheme for introducing the appropriate earth science topics at the elementary, middle, and high school years (National Research Council 1996). For students in United States middle schools, grades 5-8, the focus of the content standard includes: the earth's structure, history and position in the solar system. Although teaching students about abstract concepts such as the formation and structure of the earth and solar system may be challenging it is important to instruct them at this level so that when they graduate from high school they have a deep understanding of earth science concepts. This also includes having knowledge of natural processes and cycles, a sense of time scales, which is a concept that is difficult for some adults, and the continuous evolving of subsystems (Mayer \& Armstrong 1990; Kortz \& Murray 2009).

One fundamental aspect of learning about the structure of the earth for students in the middle grades is based on their knowledge of the earth structure, abilities to conduct experimental observations and describe geological conceptions of rock formations and property identifications. In order for students to develop an understanding of the geological aspects of the earth they must possess the skills to make good observations and clearly explain the relevance of the properties they discover. According to the National Science Education Standards (National Research Council 1996) students at the middle and high school level have the ability to record observations and distinguish characteristic properties. Having good observation techniques allow students to better understand the geochemical and geophysical processes involved in learning about the structure and history of the earth. In conducting activities such as describing and classifying rock types, middle school students have some level of experience and expertise as they are able to make observations based on their knowledge of history and rock formations (Ault 1998; Ford 2005). Rock identification tasks at

${ }^{*}$ Correspondence to: griffina@uncw.edu 
the middle school level can help students further develop their skills of observation and enhance use of scientific inquiry as they employ knowledge, observations, ideas, and questions (National Research Council 1996, p. 143). This paper explores how middle school students use observation skills to make distinctions among samples and describe the geological relevance of the properties of the samples identified. Often time presented during the elementary geology curricula, rocks and minerals tasks taught at the middle school provides learner the ability to make connections between rock and mineral properties to rock formations. As noted by Ford (2005) students will have difficulty understanding the task if they are not able understand how the properties they observe link to the geological processes involved in the earth's formations.

A critical element for understanding geological processes for middle school students and even older students can be identified by their cognitive understanding of rock formations and structure and the ability to explain and describe the relevance of properties explored in rock or mineral samples. According to research studies (Blake 1999; Ford 2005; Happs 1982, 1985; Lillo 1994; Oversby 1996; Marques \& Thompson 1997; Russell Bell Longden \& McGuigan 1993; Sharp Mackintosh \& Seedhouse 1995) conducted in the United States and Europe, children are able to develop conceptual understandings of the geosphere and its physical properties such as rocks and minerals and structural makeup. However, students' explanations and descriptions of geological aspects are limited as compared to geologists that have complex understandings of the theoretical constructs specific to earth science. Efforts have been made to transform the science curriculum to meet the needs of the learners by offering hands-on, inquiry-based earth science activities for learning these concepts (American Geological Institute 2006; Ault 1982; Blake 2004; Johnson 2004; Smith 1988). Even with these changes in the curriculum, some middle grades students continue to have difficulty grasping an understanding of many of geological processes, therefore failing to comprehend the properties and structure of the geosphere. In some adults it has been noted that they also have difficulty connecting the theoretical constructs of the earth system (Hawley 2002). Finding an earth science curriculum that will result in students understanding the key properties as they relate to rock formations and the earth structure is important for science educators. We have to make sure all students have a good understanding of earth science concepts before graduating K-12 schools. Therefore, our exploration of middle schools' students' understanding of earth science concepts is guided by the task of describing and classifying rocks and these questions: 1) How do $6^{\text {th }}$ and $8^{\text {th }}$ graders approach the task of identification? And 2) How do middle school students describe rocks?

The use of models in teaching students about geological concepts has found to be common in many studies. Addressing the aspects of learning is important as we attempt to understand students' content knowledge, process and inquiry skills and epistemic understanding of the geological concepts. Blake's review of literature on children's understanding in earth science (2004) indicated that instruction that promotes cognitive change and values the use of analogies serves as the focus of research models in teaching novices about geological concepts. Although many studies have shown providing relevant analogies to children can help scaffold their knowledge of concepts these children oftentimes revert to "non-scientific" explanations of concepts outside of classroom settings (Blake 2004; Happs 1984). In this study we implemented instruction to examine middle school students" transition from "non-scientific" to "pro-scientific" explanation of how rocks and minerals are described and classified. "Pro-scientific" is similar to Blake's (2004) concept "protoscientific" in which learner utilizes both prior knowledge and experiences, unscientific in nature, along with acquired scientific conceptions to explain a phenomena or concept.

Research studies also indicate that tasks presented at a superficial level can limit students' understanding of the earth (Happs 1982; Blake 2004; Ford 2005; Dal 2006). Hawley (2002) reported that children don't have a good understanding of rocks and neither do adults. He pointed out how characteristics that were salient to some of the students were not those characteristics that scientists use to identify rocks. Ford (2005) observed two classes of third graders who wrote descriptions of rocks and minerals as part of an activity in an earth materials unit. Ford reported that the descriptions that students wrote were not always the ones important for the identification of rocks and minerals. For example, some of the observations focused on characteristics of rock that had nothing to do with their origin but more with the characteristics of wear and tear, for example chipping. Ford (2005) concluded that students may not recognize those characteristics that are defining ones for a particular rock but may focus on those characteristics that are more obvious. Colors were most often used to identify minerals and texture was used most frequently for rocks. However, texture was not linked to grain size but to the feel of the rock. Oversby (1996) examined the topic of rock identification with middle and high school students and college students who were post graduate science teachers and post graduates not in a science field and found that the topic was difficult for all participants. He proposed that part of the 
issue with understanding rocks is the use of common terms that do not align with the definition of a rock. For example, one student defined a stone as a "loose rock". He felt lack of understanding of what defined a rock was a barrier to any further understanding. In an examination of eighth graders' discussions of the rock cycle Rosenberg, et al. (2006) noted that students try to use vocabulary that is in the unit whether or not they know what the word means.

\section{METHODS}

\section{Setting and participants}

The study focuses on middle school students enrolled in an optional course offered at the local middle school for $6^{\text {th }}$ and $8^{\text {th }}$ grade students. As a naturalist study, the site of the research and subjects were chosen to provide us with rich information to best answer our exploratory questions. We employed this qualitative approach to identify the conceptions of students as they approached the task of describing and classifying rock types. The research study took place at a rural middle school located in southeastern United States. The student population consisted of students from varied socioeconomic status and ethnicities. Self-selected small groups consisting of three students worked through the small group activities throughout the term of the project. During the 6 week period of the course, several earth science topics were selected for study including maps and mapping, rocks, stratigraphy, and volcanoes. Middle grade students respond best to actively constructing understanding so instructional activities were chosen with this characteristic in mind. Topics were selected for their alignment with the state's Standard Course of study and for their spatial components since spatial cognition was the overarching focus of the large scale study.

The study examines the tasks assigned to $6^{\text {th }}$ grade and $8^{\text {th }}$ grade students enrolled in the six week elective science course focused on earth science topics. The classes consisted of 17 and 18 students respectively. These students were selected by the principal; the criteria for selection were to have a classroom with student demographics that matched that of the school, and to have students who had a scholastic grade average for their class of 85 percent or better. These criteria were used to promote the exploratory study and to ensure enrolled students were motivated to complete the tasks and also increase the chance that students would be willing and able to communicate their ideas to the researchers as well as their peers. The teachers of the course were university science education faculty members who designed the instructional content of the course. The teachers were knowledgeable of the earth science curriculum and were capable of employing a constructivist model of teaching and learning (Dal 2007) (See Table 1).

Table 1. Breakdown of sixth and grade students by ethnicity and gender

\begin{tabular}{lccc}
\hline & $6^{\text {th }}$ & $8^{\text {th }}$ & Total \\
\hline Ethnicity & 6 & 6 & 12 \\
African American & 6 & 10 & 21 \\
Caucasian & 11 & 2 & 2 \\
Hispanic & 0 & 18 & 35 \\
Total & 17 & 9 & 18 \\
Gender & & 9 & 17 \\
Males & 9 & & \\
Females & 8 & & \\
\hline
\end{tabular}

\section{D GeoMapping}

The exploratory course was called, "3D GeoMapping" and included three modules dealing with 2D and 3D spatial objects such as flat maps, contour maps and sub-surface mapping. There was no textbook used for this course. Most of the activities were carried out in small groups of 3-4 members (six groups per class) with whole group discussions following to assist students with making connections between activities and related concepts. Student groups were self selected and instructed to work as equally contributing members and to come to a consensus before recording answers.

\section{Data collection and analysis}

For this study, researchers observed and collected notes on students' approaches throughout the six week course. The primary data sources included transcripts of students' verbal interactions and videotapes during small group work. We specifically relied on students' work and transcribed observations as they identified the rocks samples. Analyses of the subset of activities were initially coded for underlying themes using constant 
comparative analysis (Glaser \& Strauss 1967; Lincoln \& Guba 1985). Final coding emerges the themes from the data, which is a reflection of the students' answers as they completed the rock description and classification tasks.

\section{Description of activities}

Rock identification. This activity began with students examining examples of seven numbered sedimentary rocks and recording observable characteristics of each rock. Some characteristics that students were to record were identified for them (color, grain size, hardness, presence of fossils); they could choose to record any other observable qualities they thought were important. Then they were given a chart with the names of the seven sedimentary rocks followed by a picture, a list of observable qualities and the depositional environment. They were to identify the seven types of sedimentary rocks they had been given by comparing their observations with the descriptions on the key. They then answered a sheet that asks them to compare the origins of the different types of rocks, and the environmental conditions under which they were formed. The approach of the small groups in grades 6 and 8 to describe and classify the rocks was analyzed and is reported in the results section (See Table 2).

Table 2. Handout students used to complete task. modified worksheet from Ward (1999) Natural Science Establishment

\begin{tabular}{|c|c|c|c|}
\hline $\begin{array}{l}\text { Sample } \\
\text { Number }\end{array}$ & Observable Characteristics & Rock Name & $\begin{array}{c}\text { Depositional Environment } \\
\text { (Probable) }\end{array}$ \\
\hline 1. & $\begin{array}{l}\text { This rock is very smooth and thin. It is very light- } \\
\text { weight. It has a fossil of a leaf inside. They have } \\
\text { small grains. }\end{array}$ & Carbonaceous shale & Swamp, lowlands \\
\hline 2. & $\begin{array}{l}\text { It has a grayish color. Its' smooth. It's not too } \\
\text { heavy. They have small grains. It has white-chalky } \\
\text { stuff on it }\end{array}$ & Argillaceous shale & River, delta, muddy sea \\
\hline 3. & $\begin{array}{l}\text { It is clear. It is smooth. It is moist, oily, and slick. It } \\
\text { has a big grain size. It is not too heavy. It looks like } \\
\text { an ice cube } \\
\text { Smells like vanilla \& cinnamon }\end{array}$ & Halite (rock salt) & Salt Lake \\
\hline 4. & $\begin{array}{l}\text { It is hard and rough. It reminds me of brick. The } \\
\text { grain size is rather small. It is light. It is not real big. } \\
\text { Smells like dirt }\end{array}$ & Sandstone & Beach, river or delta \\
\hline 5. & $\begin{array}{l}\text { It is rough. There are lots of different colors of } \\
\text { rocks. It is also made of dirt. It looks like a cookie. } \\
\text { Is rounded. It is a chunk of mud } \\
\text { Smells like burnt rubber }\end{array}$ & Conglomerate & Beach, river \\
\hline 6. & $\begin{array}{l}\text { This rock is black. It is light. It is very shiny. It is } \\
\text { smooth on the sides and rough on the top. The } \\
\text { grain are bigger }\end{array}$ & Coal & Swamp \\
\hline 7. & $\begin{array}{l}\text { This rock is gray and white. It is heavy and rough. } \\
\text { It has fossils of seashells inside. The grains are } \\
\text { rather larger }\end{array}$ & Fossiliferous limestone & Clear shallow marine sea \\
\hline
\end{tabular}

\section{RESULTS}

\section{Strategies used by $6^{\text {th }}$ graders}

Five of the six groups of $6^{\text {th }}$ graders used very similar strategies in identifying the rocks. Four of the six groups immediately identified halite because it was so clearly distinguishable when compared to the other samples. There were a number of strategies, which emerged to identify the other rocks but most noticeable as a poor strategy was the students' attempts to match the pictures on the chart (key) with the rocks and minerals. The pictures on the chart were small and in black and white so characteristics of individual rocks were difficult to distinguish. Nevertheless, students would put the sample next to each picture, occasionally making a correct identification from the picture. In five of the six groups, this strategy was used by a least one member of the groups. Another favorite strategy of sixth graders was to immediately default to color. Sometimes a member of the group would recognize that more than one rock had the same color. In other cases, the first rock or mineral that was listed on the sheet that matched the sample's color was chosen. Prior knowledge occasionally played a role. For example, one group member had experiences with coal and was 
able to immediately identify it. In two groups the presence of fossils was used as a determining factor. In one group the members did not understand there was a one-to one correspondence between the samples and the rocks and minerals listed on the key. So the members depended, rather unsuccessfully, to identify samples based on prior knowledge. Students held on to alternative conceptions for identifying rocks and minerals such as use of smell and color rather than using key and pointing out salient features of the samples (See Figure 1).

\section{Strategies used by $8^{\text {th }}$ graders to identify rocks}

As with the sixth graders, halite was readily identified by the groups. For all six groups of eighth graders color was the usually the first characteristic they tried to match. However, when group members would notice that color did not narrow down the choice to one sample they looked for other characteristics they had observed. Although some group members looked at pictures that was not a primary strategy and confirming

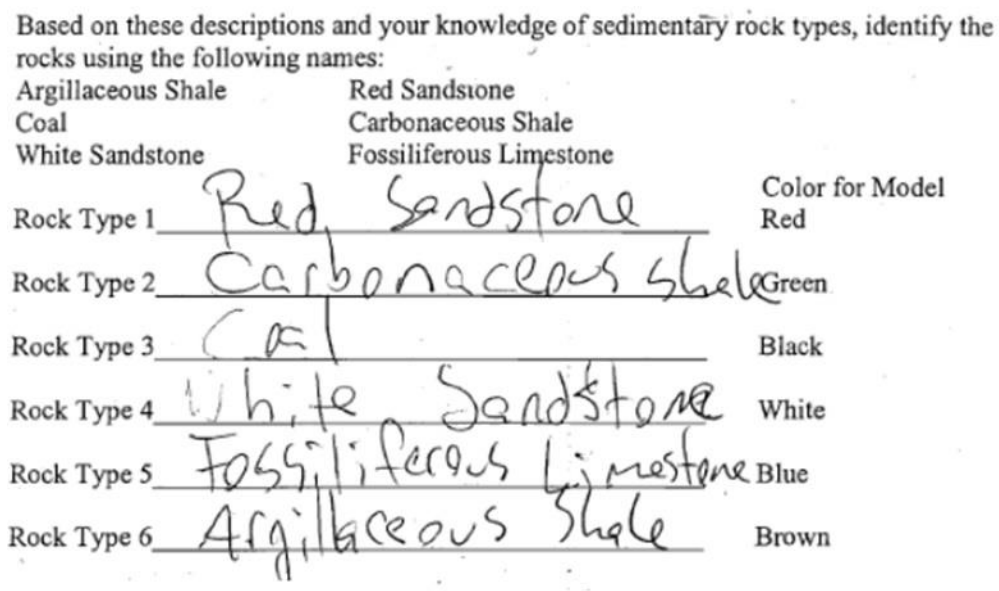

Based on these descriptions and your knowledge of sedimentary rock types, identify the rocks using the following names:

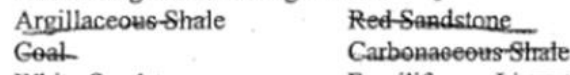

Based on these descriptions and your knowledge of sedimentary rock types, identify the rocks using the following names:

$\begin{array}{ll}\text { Argitlaccours-Shale } & \text { RedSaandstone } \\ \text { Coat- } & \text { Carbonaceousstrade } \\ \text { White Sandstone } & \text { Fossiliferous Limestone }\end{array}$

White Sandstone Fossiliferous Limestone Color for Model

Rock Type 1_Red Sandstone Red

Rock Type 2 Carbonrcens shat Green

Rock Type 3__ COQl Black

Rock Type 4_white sandstone white

Rock Types Fossiliferans limesone Bluo Rock Type 6 Argillaceg hs shale Brown

Figure 1. Student sample responses 
characteristics were always sought. Although eighth graders were slightly more successful in identifying the rocks and minerals, errors were made when students did not recognize the importance of a particular characteristic such as presence of a type of fossil (See Table 3).

\section{DISCUSSION}

Saliency and scale both played a key role in the completion and interpretation of the students' tasks. Characteristics most likely to appear salient have been used during prior experiences as defining properties and retrieved from long-term memory for use in working memory. To experts, (such as science teachers), salient characteristics are obvious but not to novices. For example, without an understanding of the origin of certain rock, characteristics such as grain size, texture, or cleavage may not be salient while more common characteristics such as color, shape, or cracks may be. Therefore, students focus on, what to them, are the features that will be helpful in identification of the rocks. Color is one of the earliest characteristics used for identification (typically before preschool age). Without experiences in using salient features for rock identification then characteristics used for prior identification tasks will not be accessed.

In many cases, color is the obvious default. Therefore students must have the experience of using and understanding how other characteristics are the salient ones for rock identification tasks. Then when faced with rock identification tasks at a later time, prior experiences will assist students with bringing to working memory the salient features appropriate for the task.

In comparison to Hawley (2002 p. 370) approach to teaching students about rocks our pedagogical approach of scaffolding and using relevant analogies allowed the students to "determine, recognize and explain fundamental textural differences in a range of rocks and relate them to specific rock properties." By focusing on the grain relationships of rocks and using an inquiry approach during course instruction, students were able to acquire knowledge to think scientifically about rocks and earth science concepts. Although the terminology used by the students in our population as they described the rocks showed some consistency, they may not be fully representative of all students in this middle school population. Additional research is needed to determine if all middle school students hold on to similar conceptions of knowledge when describing and classifying these geological structures.

\section{IMPLICATIONS}

So clearly a teacher must consciously make salient key characteristics. Students at this age, 11-14, may have little experience with constructing knowledge for themselves or lack sufficient prior knowledge to pick out salient features. One suggestion might be to limit students' descriptions of rock characteristics to those most important to identification. This might encourage the development of rock type identification schema that includes salient features. Some researchers propose that students must have a grasp on geological time to understand geology and as a first step must be able to engage in diachronic thinking. Diachronic thinking as described by Montangero (1996) occurs when an individual must mentally construct change as it has happened over time. He reported that children as young as 10-11 could engage in diachronic thinking but only if they had knowledge of the particular targeted concept. In other words, students may be able to think about and follow the changes over time as it relates to aging of a pet or passing of the seasons. But without the necessary geological information, understanding a concept such as deposition may not be possible even if diachronic thinking is possible.

Therefore earth science instruction should provide scaffolding and the use of relevant analogies to enable students' transition from "non-scientific" explanation of geologic concepts to "pro-scientific" and eventually scientific explanations of how rocks and minerals are described and classified.

\section{REFERENCES}

American Geological Institute, $2006 . \quad$ Curriculum materials for teachers. Http://www.agiweb.org/education/teachers/curriculum_materials.html (Accessed 28 June 2010.)

Ault, C. R., 1982. Time in geological explanation as perceived by elementary-school students. Journal of Geological Education, 30, pp.304-309.

Ault, C. R., 1998. Criteria of excellence for geological inquiry: The necessity of ambiguity. Journal of Research in Science Teaching, 35(2), pp.189-212.

Blake, A., 1999. Children's understanding of aspects of earth science at key stage 2: Conceptions and conceptual change. (PhD thesis, University of Newcastle). 
Blake, A., 2004. Helping young children see what is relevant and why: Supporting cognitive change in earth science using analogy. International Journal of Science Education, 26, pp.1855-1873.

Blake, A., 2005. Do young children's ideas about the Earth's structure and processes reveal underlying patterns of descriptive and causal understanding in earth science. Research in Science and Technological Education, 23, pp.59-74.

Dal, B., 2006, The origin and extent of student's understandings: The effect of various kinds of factors in conceptual understanding in volcanism. Electronic Journal of Science Education, 11, pp.38-59, viewed 2 August 2010 http://ejse.southwestern.edu

Dal, B., 2007. How do we help students build beliefs that allow them to avoid critical learning barriers and develop a deep understanding of geology?.Eurasia Journal of Mathematics, Science \& Technology Education, 3(4), pp.251-269.

Ford, D. J., 2005. The challenges of observing geologically: Third graders' descriptions of rock and mineral properties. Science Education, 89, pp.276-295.

Hawley, D., 2002. Building conceptual understanding in young scientists. Journal of Geoscience Education, 50, pp.363-371.

Happs, J. C., 1982. Some aspects of student understanding of rocks and minerals. University of Waikato: Science Education Research Unit Working Paper.

Happs, J. C., 1984. The utility of alternative knowledge frameworks in effecting conceptual change: Some examples from the earth sciences. (PhD thesis, University of Waikato, New Zealand.

Happs, J. C., 1985. Regression in learning outcomes: Some examples from earth sciences. European Journal of Science Education, 7, pp.431-433.

Johnson, C. J., 2004. NANA "Rocks" problem-based learning. Science Scope, 28, pp.48-49.

Kortz, K. and Murray, D., 2009. Barriers to college students learning how rocks form. Journal of Geoscience Education, 57(4), pp.300-315.

Lillo, J., 1994. An analysis of the annotated drawings of the internal structure of the Earth made by students aged 10-15 from primary and secondary schools in Spain. Teaching Earth Sciences, 19(3), pp.83-87.

Lincoln, Y. and Guba, E., 1985. Naturalist inquiry. Newbury Park CA: Sage.

Marques, L. and Thompson, D., 1997. Portuguese students' understanding at ages 10-11 and 14-15 on the origin and nature of the earth and the development of life. Research in Science and Technological Education, 15, pp.29-51.

Mayer, V. J. and Armstrong, R. E., 1990. What every 17-year old should know about planet earth: The report of a conference of educators and geoscientists. Science Education, 74, pp.155-165.

Montangero, J., 1996. Understanding changes in Time: The development of diachronic thinking in 7- to 12-year old children. Bristol, PA: Taylor \& Francis.

National Research Council, 1996. National science education standards. Washington, DC: National Academy Press.

Oversby, J., 1996. Knowledge of earth science and the potential for its Development. School Science Review, 78, pp.91-97.

Rosenberg, S., Hammer, D. and Phelan, J., 2006. Multiple epistemological coherences in an eighth grade discussion of the rock cycle. The Journal of Learning Sciences, 15, pp.261-292.

Russell, T., Bell, D., Longden, K., and McGuigan, L., 1993. Primary SPACE research report: Rocks, soil and weather Liverpool: Liverpool University Press.

Sharp, J. G., Mackintosh, M. A. P. and Seedhouse, P., 1995. Some comments on children's ideas about Earth structure, volcanoes, earthquakes and plates. Teaching Earth Sciences, 20(1), pp.28-30.

Smith, G. S., 1988. Gaps in the rock and fossil records and implications for the rate and mode of evolution. Journal of Geological Education, 36, pp.143-146. 